\title{
Ensaio sobre a insustentável leveza do conceito de Qualidade
}

\author{
Paulo Eduardo Sobreira Moraes* \\ Maura Regina Franco**
}

Guilherme R. S. Souza e Silva***

\begin{abstract}
Resumo
O presente artigo apresenta ponderações sobre o conceito de qualidade, analisando o tema sob duas perspectivas: a qualidade gerada a partir da diferença e a qualidade oriunda da igualdade ou regularidade. Posteriormente são apresentadas as relações entre as noções e as percepções conceituais do que é entendido como qualidade. Argumenta-se que essas percepções não são excludentes entre si, mas que de fato podem ser consideradas complementares. A partir dessas idéias associam-se tais percepções à qualidade pela diferença e pela igualdade. $\mathrm{O}$ artigo também discute a qualidade sob três óticas: a do processo, a dos atributos do produto/serviço e a da utilização das ferramentas da qualidade. Avalia-se ainda a relevância dos processos de certificação de qualidade e a sua função ao levar a um consenso sobre o que se entende por qualidade, naquele escopo específico. Finalmente discute-se a natureza leve, e de certa forma insustável, do conceito de qualidade.
\end{abstract}

\begin{abstract}
This paper presents ideas about the concept of Quality, analyzing the issue regarding two perspectives: quality generated from difference and quality derivate from equality or regularity. In the sequence, relationships between the notions and conceptual perceptions of quality are presented. One can understand that these perceptions are not mutually exclusives, but in fact they can be considered complementary. Working on these ideas, it is possible to associate the perceptions of quality from difference and from parity. The paper also discusses quality under three aspects: the process, the products/services characteristics and the use of quality tools. The relevance of the quality certification process and its function to help understand the concept of quality in a definite scope is is also discussed. Finally, the paper argues about the light, and unsustainable in a certain way, nature of the concept of quality.

\footnotetext{
* Professor do Setor de Educação Profissional e Tecnológica da UFPR. Doutor em Engenharia Florestal pela UFPR.

** Professora do Setor de Educação Profissional e Tecnológica da UFPR. Doutora em Engenharia Florestal pela UFPR

*** Professor do Setor de Educação Profissional e Tecnológica da UFPR. Mestre em Desenvolvimento Econômico pela UFPR.
} 
Presente no cotidiano das organizações, da sociedade, do conjunto do mercado e patente em cada tomada de decisão do consumidor, a qualidade é um vocábulo plurívoco, à medida que é utilizado de formas várias e em contextos diversos. Ontologicamente, conforme Moraes (2007), a qualidade como atributo é função da comparação entre objetos: um tem qualidade porque é melhor que o outro sob algum sentido. Ser melhor que algo sob algum aspecto confere qualidade ao objeto em foco - dois objetos de uma mesma categoria podem ser dispares entre si sob algum aspecto, e daí decorre a eleição de um melhor. É da diferença que nasce o conceito de qualidade, e não da igualdade.

O objeto entendido de modo concreto (como um carro que é melhor que outro, pois tem maior potência), como sistema de ação ou de produção (como uma linha de montagem que é melhor que outra porque é mais produtiva), como sistema estruturado de idéias, saberes e conhecimentos (como uma teoria é superior a outra porque corresponde melhor à realidade dos fatos) ou como condição situacional (como um serviço que atende melhor a um cliente do que um outro) pode ser avaliado, pode ser compreendido e pode ser comparado com seus similares. E é a partir da diferença que emerge da comparação que se constitui o que tem maior qualidade ao se eleger o mais perfeito, o mais desejável, o mais acurado.

Deleuze (1968), em antológico trabalho, corrobora a perspectiva apresentada acima; assim como Dias Neto (2010), Campos (2009), Loures (2009), Onusic (2009), Franco (2008), Takashina \& Flores (1997) e Sumanth (1994).

Mas, o objeto pode ser comparado - no sentido de cotejado - com o que lhe é intrínseco. Dois objetos diversos, mas análogos, podem ser confrontados com outros similares ou entre si. Colacionar o objeto em função de sua própria existência pode ser igualmente uma fonte geradora do conceito de qualidade.

O objeto em si mesmo pode ser ponderado quanto ao que dele se quer ou ao que dele se espera. A regularidade de performance ou desempenho de uma máquina, lhe confere qualidade desde que o que dela se espera seja alcançado e que seja tal regularidade o que se queira. Decorre de tal percepção que a qualidade emerge conjuntamente da noção de igualdade - em contraposição ao que se apresentou nos parágrafos anteriores.

É em razão de ser sempre igual que um objeto entendido como algo concreto (como todos os carros de uma determinada fábrica apresentarem exatamente a mesma potência), como sistema de ação ou de produção (como uma linha de montagem que é exatamente regular em sua produtividade no decorrer do tempo), como sistema estruturado de idéias, saberes e conhecimentos (como uma teoria que atende a todos os caso a que se aplica) ou como condição situacional (como um serviço que atende a todos do mesmo modo) pode ser 
avaliado, pode ser compreendido e pode ser comparado consigo mesmo e é da igualdade que emerge da comparação do objeto consigo mesmo que se constitui o ter maior qualidade.

Campos (2009) corrobora tal perspectiva, assim como Mello (2002), Medaets (2003) e Benevides et al. (2007).

O conceito de qualidade é leve, na medida em que se apresenta flexível e plurívoco; por outro lado é insustentável se os que são concernidos a utilizarem tal conceito não o usam sob a mesma perspectiva; isto é, se pressuporem que o conceito de qualidade que adotam é de compreensão, domínio e uso do interlocutor (seja ele interno ou externo à organização. Moraes (2000) ressalta que os concernidos na construção do diálogo o façam sobre base de entendimento pleno entre si e sobre o que lhes é concernido - ainda que guardem peculiaridades de compreensão entre si.

Notadamente, em concordância com Reeves \& Bednar (1994), Maximiniano (2000) e Moraes (2007), se afiança que percepções conceituais de qualidade têm sido associadas a noções de excelência, valor, especificações, conformidade, regularidade e adequação ao uso; ao que se acrescenta a noção de satisfação. Abaixo, inspirado em Maximiniano (2000, p. 186) e Moraes (2007, p. 71 a p. 73), se relaciona tais noções a percepções conceituais de qualidade, acrescentadas outras, conforme segue:

Tabela 1. Relação entre noção e percepções conceituais de Qualidade

\begin{tabular}{|c|c|}
\hline Noções & Percepção Conceitual \\
\hline Excelência & $\begin{array}{l}\text { - Qualidade é o que há de mais } \\
\text { apurado e primoroso que se possa } \\
\text { ter ou fazer. } \\
\text { - Qualidade é o que há de melhor } \\
\text { performance em uma categoria. } \\
\text { - Qualidade é o que há de melhor } \\
\text { quando comparado a similares de } \\
\text { mercado ou de condições de } \\
\text { produção. }\end{array}$ \\
\hline
\end{tabular}




\begin{tabular}{|c|c|}
\hline Valor & $\begin{array}{l}\text { - Qualidade é o atributo inerente } \\
\text { àquilo que é mais caro em sua } \\
\text { produção. } \\
\text { - Materiais ou processos mais caros } \\
\text { ou raros dão qualidade ao objeto ou } \\
\text { processo. } \\
\text { - Qualidade é o atributo intrínseco } \\
\text { daquilo que, em função de seu valor } \\
\text { atribuído, tem o preço mais elevado } \\
\text { em comparação com seus similares } \\
\text { concorrentes. } \\
\text { O que é único, raro e mais desejável } \\
\text { tem maior qualidade. } \\
\text { Qualidade é o atributo intrínseco } \\
\text { tido como minimamente aceitável e } \\
\text { maximamente desejável em função } \\
\text { do quanto se pode pagar. } \\
\text { A exclusividade de um produto ou } \\
\text { serviço que faz com que este seja } \\
\text { desejável, raro e caro lhe confere } \\
\text { maior qualidade. }\end{array}$ \\
\hline Especificações & $\begin{array}{l}\text { - A determinação especificada daquilo } \\
\text { que se deseja produzir ou servir } \\
\text { confere maior qualidade ao produto } \\
\text { ou serviço. } \\
\text { - A característica de definição } \\
\text { pormenorizada de um projeto de } \\
\text { produto ou serviço faz com que o } \\
\text { mesmo tenha maior qualidade. }\end{array}$ \\
\hline Conformidade & $\begin{array}{l}\text { - Qualidade é a condição de execução } \\
\text { de um serviço ou a produção de um } \\
\text { bem na maior consonância e } \\
\text { concordância possível a seu projeto. }\end{array}$ \\
\hline
\end{tabular}




\begin{tabular}{|c|c|}
\hline Regularidade & $\begin{array}{l}\text { - Qualidade é a capacidade de } \\
\text { reproduzir um bem ou serviço } \\
\text { sempre do mesmo modo e com os } \\
\text { mesmos predicativos em } \\
\text { conformidade com um padrão. }\end{array}$ \\
\hline Adequação ao uso & $\begin{array}{l}\text { - Qualidade é condição de uso de um } \\
\text { produto em concordância à } \\
\text { utilização que tem para o mesmo ou } \\
\text { efetivação de um serviço em } \\
\text { consonância com o que se espera do } \\
\text { mesmo. }\end{array}$ \\
\hline Satisfação & $\begin{array}{l}\text { - } \text { Qualidade é a virtude de um produto } \\
\text { ou serviço que satisfaz, ou agrada a } \\
\text { quem dele se serve. } \\
\text { - } \text { Qualidade é a virtude de um produto } \\
\text { ou serviço que satisfaz, ou agrada a } \\
\text { quem o realiza seja por satisfação } \\
\text { pessoal ou por remuneração. } \\
\text { Qualidade é a virtude de um produto } \\
\text { ou serviço em atender de modo } \\
\text { pleno (e mesmo exacerbado) às } \\
\text { expectativas de quem o consome. }\end{array}$ \\
\hline
\end{tabular}

As percepções conceituais expostas não são excludentes entre si e, de fato, podem se complementar; isto é, satisfação e adequação ao uso podem se potenciar mutuamente na percepção do que é qualidade, por exemplo. As noções de regularidade e especificações também estão afins quanto à qualidade no processo produtivo.

Pode-se ressaltar que entre igualdade e diferença como entes fundentes do conceito insustentável e leve da qualidade é possível fazer a seguinte correlação:

1. Baseado em diferenças

- Satisfação

- Valor

- Excelência 
2. Baseados em igualdades

- Adequação ao uso

- Regularidade

- Conformidade

- Especificações

É interessante perceber que, se a qualidade é mais facilmente percebida no paradigma de produção industrial pelas possibilidades de igualdade, as diferenças são mais associadas ao que o consumidor entende por qualidade. Insustentável seria que aqueles que produzem tenham posição oposta daqueles que usufruem - não fosse a leveza do conceito da qualidade.

Mercadologicamente, o ideal é que os que produzam atendam às necessidades e expectativas dos que consomem, assim como também é ideal que os que consomem percebam a qualidade da forma como os que produzem a entendem. Franco (2008) corrobora tal assertiva.

O conceito de Qualidade pode se desdobrar a partir do quadro, de modo que a potencialização de uma perspectiva junto à outra pode gerar um novo entendimento mais oportuno do que ambas isoladamente propiciam.

Moraes (2004), por outro lado, transparece pelo menos três concepções do que vem a ser Qualidade; a saber:

i. Qualidade como processo de ordenação das atividades organizacionais quanto mais uma empresa ordena sua atividade mais apresenta qualidade;

ii. Qualidade como atributos do produto - quanto mais atributos intrínsecos ao produto, quando comparado aos produtos concorrentes em mesma faixa de consumo, quanto mais agradável ao consumidor final, quanto mais barato em comparação com os produtos concorrentes em mesma faixa de consumo e quanto mais aprimorado o processo produtivo que dá origem a produto então tanto maior será a qualidade; e,

iii. Qualidade como uso de ferramentas de gestão, pelo uso de programas

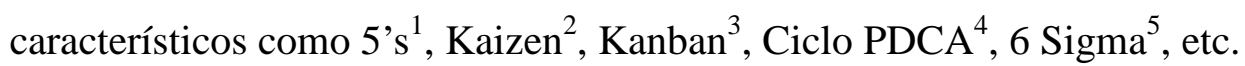

\footnotetext{
${ }^{1}$ 5's ou Houseekiping é uma ferramenta de gestão que se propõe a processualmente dar ordem e mantê-la com limpeza (envolvendo o conceito de saúde física e mental, além de higiene), organização, segurança, utilizando recursos de modo otimizado às empresas e organizações de um modo geral. Nota explicativa.

${ }^{2}$ Kaizen é uma ferramenta de gestão que imbui em todos os participantes a expectativa do aprimoramento contínuo (de seu setor, da organização como um todo e até o aprimoramento pessoal) nas atividades que desempenham. por meio de uma atitude pró-ativa e participativa.

${ }^{3}$ Kanban é uma ferramenta de gestão que permite o acompanhamento da produção por meio do registro em
} 
Em seu trabalho, o autor citado não estabelece o que é qualidade, mas há um transluzir de uma concepção múltipla sobre o que é qualidade. Assim, qualquer uma das abordagens que se apresenta pode ser entendida como equivalentes entre si.

Assim, Qualidade, em um sumo dos três posicionamentos, é a um só tempo o conjunto de ações organizacionais que garantem sua auto-organização para que se possa efetivamente produzir os itens que a privilegiem no mercado por meio de ferramentas e programas.

Introduz-se, aparentemente, para além da insustentabilidade entre qualidade baseada em igualdades e qualidade baseada em diferenças uma nova perspectiva: qualidade baseada no uso de ferramentas de gestão. A terceira via seria de fato uma alternativa possível de unificação ontológica entre diferenças e igualdades na constituição do conceito de qualidade não fossem tais ferramentas em sim mesmas estratégias ou de diferenciação pelo aprimoramento (caso do kaizen) ou de busca da igualdade de comportamento dos sujeitos (caso do 5'S) ou do processo produtivo (caso do 6 Sigma), ou do emprego preestabelecido e portanto regular - igual - de metodologias (caso do kanban ou do Ciclo PDCA).

Isto porque a qualidade, como processo ordenado, traduz o anseio pela regularidade, da igualdade, das atividades no tempo - ainda que se alterem como prática. E como aprimoramento, diferenciação, a qualidade é indutora de distinção entre situações ou alternativa - seja por atributos de produtos, processos ou de itens que determinem a opção do consumidor.

Schulz (2008) aponta que a complexidade da produção leva a soluções criativas que unem fatores aparentemente diversos entre si, o mesmo se poderia aplicar ao conceito da qualidade no sentido de que sua insustentabilidade é antes resultante da complexibilidade inerente não só à produção, mas às organizações em suas constituições particulares, diversas e intrínsecas.

Dimana que o conceito de qualidade, fluido e precário, passa a ser consolidado e perene, na medida em que se torna necessariamente determinado pelos concernidos que dele se utilizam. Uma vez acordado o que se quer ter por qualidade vale o convergido. É por tal razão que normas de certificação da qualidade têm valor aos que a elas aderem e não em si

cartões de todas as operações que estejam sendo realizadas ou que se realizaram em um lote de itens bem como as especificações deste lote e informações que lhe sejam afetas.

${ }^{4}$ Ciclo PDCA, ou Ciclo de Shewhart, ou Deming Cicle é uma ferramenta de gestão que preconiza a consecução das etapas de planejamento, execução, controle e ação corretiva (sendo o caso de verificação de desvios na oportunidade do controle) nas atividades de aprimoramento da organização, em especial no acompanhamento do processo produtivo que visa o controle da qualidade.

5 Sigma é uma ferramenta a um só tempo de gestão quanto de controle do processo produtivo que atende à perspectiva de nulificação do número de defeitos no processo produtivo tanto pela redução de oportunidades de defieto quanto pela regularização dos processos produtivos mediante controle. 
mesmas.

Isto é, uma organização, processo ou produto/serviço certificado não tem qualidade em um sentido universal (porque a qualidade é um conceito insustentável nos termos em que este trabalho justifica tal afirmação), mas os que a adotam e optam pela norma certificadora e seus preceitos entendem que seja factual reconhecer tal processo, ou produtos/serviços ou organização como tendo qualidade. Similarmente, não há produto/serviço ou processo, ou organização que não tenha qualidade se há que lhe atribua tal condição.

Seja pela adesão a normas ou pelo reconhecimento da condição independentemente de normas, os produtos/serviços, processos e organizações devem ser ponderados quanto à qualidade (muito embora seu conceito seja insustentável e leve). Intuitiva e racionalmente, subjetiva e objetivamente é possível o discernimento sobre a qualidade de algo ou de alguma coisa - pela lógica da diferenciação ou igualdade - e é esta possibilidade que mantém a qualidade como busca da gestão empresarial, pública, estratégica, etc.

Da qualidade em si mesma - Paladini (2004) discute sobre se o correto seria da qualidade ou de qualidade, aqui se adota da qualidade - como fato (da veritas latina), como verdade lógica (da alétheia grega), como convenção (da emeth hebraico) se tem o amparo à discussão científica sobre si mesma e sobre suas implicações tanto a nível organizacional quanto ao nível social. Não importa o conceito da qualidade: ela mudou as organizações e a sociedade, mudou o consumidor e o que oferece produtos/serviços no mercado, mudou o cidadão em relação ao Estado, mudou as relações sociais já todos querem qualidade em suas vidas e qualidade de vida

Um vasto campo de investigação científica se tem apresentado diante de pesquisadores das ciências sociais (aplicadas e puras), das engenharias, de todos os ramos da ciência: a Qualidade - como fenômeno inclusive sócio-linguístico, histórico, econômico, etc. E como tal, sua concretude é cada vez mais patente e seus encaminhamentos cada vez mais pejados de lastro, muito embora conserve insustentável e leve suas possibilidades de conceituação e concepção. 


\section{Referências Bibliográficas}

BENEVIDES, Selene Daihas; RAMOS, Afonso Mota; PEREZ, Ronaldo. Necessidade da implementação da rastreabilidade como ferramenta de qualidade para a industrialização da manga na zona da mata mineira. In: Revista brasileira de agrociência, Vol. 13, № 1 , pags. 1924. Pelotas: UFPEL, 2007.

CAMPOS, Vicente Falconi, TQC - controle da qualidade total no estilo no estilo japonês. Nova Lima: INDGTecs, 2009.

CAMPOS, Vicente Falconi. Qualidade total: padronização de empresas. Belo Horizonte: Fundação Cristiano Ottoni, 1991.

DIAS NETO, Arilo Claudio. Seleção de Técnicas de Teste Baseado em Modelos. Tese de Doutorado. Rio de Janeiro: UFRJ, 2010.

DELEUZE, Gilles. Différence et répétition. Tese de Doutorado. Paris: Sorbonne, 1968.

FRANCO, Maura Regina. Padrões de qualidade de produtos moveleiros: um estudo de casos no pólo de Arapongas, Paraná. Tese de Doutorado. Curitiba: UFPR, 2008.

LOURES, Carlos Augusto da Silva. Razões para a Ocorrência dos Gaps de Gestão da Qualidade de Serviço: Estudo de Caso numa Organização de Transporte Metroviário. São Paulo: USP, 2009.

MEDAETS, Jean Pierre Passos. A construção da qualidade na produção agrícola familiar: sistemas de certificação de produtos orgânicos. Tese de Doutorado. Brasília: UNB, 2003.

MELLO, C. H. P. et al. ISO 9001:2000 Sistema de gestão da qualidade para operações de produção e serviços. São Paulo: Atlas; 2002.

MORAES, Paulo Eduardo Sobreira. Um espaço comunicativo entre a tecnologia ambiental, a engenharia química e a educação tecnológica. Dissertação de Mestrado. Curitiba: UTFPR, 2000 . 
MORAES, Paulo Eduardo. Introdução à gestão empresaria. Curitiba, IBPEX, 2004.

MORAES, Paulo Eduardo Sobreira. Estratégia de pesquisa sobe gestão da qualidade e da inovação tecnológica: o caso de serrarias do pólo madeireiro de Telêmaco Borba, Paraná. Tese de Doutorado. Curitiba: UFPR, 2007.

ONUSIC, Luciana Massaro. A qualidade de serviços de ensino superior - o caso de uma instituição de ensino público. Tese de Doutorado. São Paulo: USP, 2009.

PALADINI, Edson Pacheco. Gestão da Qualidade: teoria e prática. $2^{\mathrm{a}}$ Edição. São Paulo: Atlas, 2004.

SCHULZ, Ancelmo Arno. Relações complexas na administração da produção. Dissertação de Mestrado. Florianópolis: UFSC, 2008.

SUMANTH, David J. Productivity engineering and management. McGraw-Hill: College Custom Series: Miami, 1994.

TAKASHINA, Newton T.; FLORES, Mario Cesar X. Indicadores da qualidade e do desempenho. Rio de Janeiro: Qualitymark, 1997. 